\title{
Educational Leaders and the Prospective Responsiveness to the Vast Drastic Educational Changes in the Abu Dhabi Emirate
}

\author{
Mohammad Sayel Al-Zyoud ${ }^{1}$ \\ ${ }^{1}$ Chair of Education Department and Associate Professor of Educational Studies, College of Arts and Sciences, \\ Abu Dhabi University, United Arab Emirates \\ Correspondence: Mohammad Sayel Al-Zyoud, Chair of Education Department and Associate Professor of \\ Educational Studies, College of Arts and Sciences, Abu Dhabi University, United Arab Emirates. E-mail: \\ mohammed.alzyoud@hotmail.com
}

\author{
Received: September 11, 2014 Accepted: November 31, 2014 Online Published: January 27, 2015 \\ doi:10.5539/ies.v8n2p1 \\ URL: http://dx.doi.org/10.5539/ies.v8n2p1
}

\begin{abstract}
This study examines the prospective responsiveness of school leaders to the drastic educational changes currently being instituted in Abu Dhabi. The study utilizes a qualitative research approach by using a focused group interview with twenty-five teachers selected by purposive sampling from Abu Dhabi Emirate schools.

The study revealed that schools are witnessing critical and continuous changes in all areas related to school leadership, teachers, pupils, curricula, teaching methods, school culture, resources, facilities, services, and infrastructures. Many of these critical changes affect the practice of educational leaders, including policy and decision making, technology use, innovative teaching, teacher training, principal preparation, quality of school facilities and services, and parental engagement.

The prospective school leader's response to these changes, from the perspective of school leaders, is to make critical decisions to introduce and implement new technologies in schools, enhancing the quality of school curricula, teaching and learning, and educational resources and services. Furthermore, a school leader's prospective response to the drastic changes varies and depends on the availability of highly qualified leaders, financial resources, and support from educational authorities.
\end{abstract}

Keywords: change, development, education, leadership, reform, schools

\section{Introduction}

Educational change, educational reform, educational improvement, and educational development are the most common concepts that educators have discussed over the past four decades. The core idea of all these concepts is to improve the quality and efficiency of educational systems. The scope of the educational change implemented in different countries varies, depending on how important the country deems education. However, over the past twenty years, educational systems worldwide have witnessed drastic changes in many aspects of their educational systems, intended to: provide high-quality educational services to youth; equip students with the knowledge, skills, competencies, ethics, and values that they need to build their societies; improve the quality of their lives; and meet the labor market's needs.

These changes were intended to: establish a new national vision and educational aims; restructure educational systems at different levels; privatize and diversify education; increase parental and community involvement in education and management of a market-driven approach to education; ensure educational quality, standards, and accountability; increase decentralization and school-based management; enhance both teacher quality and the continuous lifelong professional development of teachers and principals; use information technology in learning and teaching; apply new technologies in management; and make a paradigm shift in learning, teaching, and assessment (Cheng 2005a, as cited in Cheng, 2009).

For example, educational development in the UK can be traced back to the 1960s; while it received only limited government support in the late 1980s and early 1990s, in the last 12 years educational development was actively supported by governmental agencies (Gosling, 2009). Some countries have started five- to ten-year reform programs; the first educational reforms of China started with fiscal and administrative decentralization as power and responsibilities were delegated to lower-level local authorities. The second series of reforms, starting in the 
1990s, was internally-focused and consisted of changes in educational ideology, curriculum, teaching approaches, and evaluation methods (Liu \& Dunne, 2009).

The most drastic changes that have been experienced by most educational systems were in the areas of school leadership, teachers, pupils, curricula, teaching methods, school culture, resources, facilities, services, and infrastructures.

Furthermore, the core changed that educational systems tried to implement were related to teaching and learning, integrating technology in education, bilingual education, and moving to student-centered education. Educational changes are necessary to cope with developments in other fields and to provide these fields with the most qualified human resources; these changes enable individuals and groups to build and belong to their societies. Educational change is developing and improving all or some of the components of educational systems. Countries across the globe used different approaches to introduce changes into their systems; some countries implemented comprehensive educational change over a certain period, and others implemented changes to some aspects of their systems. The level of change depended on the availability of resources to implement the required change and the readiness of the educational system to adapt to the new change. Therefore, different parties were involved in the process of educational change: teachers, students, parents, policy makers, and school leaders. Each party has a very important contribution to this process, but the role of the school leader has not been effective enough because of the lack of understanding of his/her role and responsibilities. School leaders are necessary in the process of change because the role of the change leader is to remove barriers and free people to use their strengths to improve the organization and make it responsive to community, regional, and national needs (Wallin, 2010). According to Wheatley (as cited in Wallin, 2010), leaders are obligated to help the whole organization examine itself, that is, to be reflective and meaningful about its activities and decisions.

This study has shed light on the prospective responses (roles) of school leaders to the drastic changes in schools. Furthermore, it attempted to identify the different roles that school leaders have played to lead their schools and achieve the intended visions and goals of the educational systems.

\section{Problem Statement}

The educational system of the Abu Dhabi Emirate was the target of many changes over the past two decades. These changes were aimed toward improving the quality of the teaching experience of students to prepare them for life and enable them to serve their communities as professionals. The changes that implemented by the educational authorities brought improvement to the quality of teachers, educational facilities, educational resources, infrastructures, assessment and evaluation, educational practices, and school culture. Despite the huge efforts to improve all of these areas, the process of change is still active and ongoing to further improve the educational system. These changes were necessary to advance the educational system to modern standards. Teachers, as one of the core elements of the educational system, apply changes in schools and have concerns regarding the response that educational leaders have toward the required changes. Taking the view of teachers into account regarding the educational changes that will be implemented in Abu Emirate schools requires schools leaders to respond differently and meet teachers' expectations in this matter. Therefore, the study tried to examine the views of teachers regarding the responses that they expected from school leaders regarding the changes that are needed for the educational system. The study answered the following question: What is the prospective responsiveness of the school leaders to the drastic educational changes currently ongoing in Abu Dhabi Emirate schools?

\section{Methodology}

This study follows the qualitative research approach through the use of the focused group interview. This technique is used to collect qualitative data by setting up a situation (the interview) that allows a respondent the time and scope to talk about his or her opinion on a particular subject. The objective was to understand the respondent's point of view rather than make generalizations about behavior. This interview used open-ended questions; some were suggested by the researcher and some arose naturally during the interview (Sociological Research Skills, 2011). In addition, this study quantified the qualitative data by calculating the frequencies and percentage of the responses of the twenty-five teachers. The percentage of responses of twenty-five teachers is interpreted in three stages: 


$$
\begin{array}{ll}
90 \%-100 \% & \text { Very High } \\
80 \%-89 \% & \text { High } \\
70 \%-79 \% & \text { Moderate }
\end{array}
$$

Source: Department of Planning and Policy Research (2006), Education Development Master Plan, Kuala Lumpur.

\section{Finding and Discussion}

High-quality leaders, with the power to act, are required to obtain a positive response from school leaders to drastic changes in educational systems. Leadership quality means what leaders have to lead educational institutions, in terms of qualifications, knowledge, experiences, skills, motivation, and values. School leaders respond positively to changes in educational systems if they are involved, by the top and middle educational leadership, in the preparation and planning of the new changes. This is essential to make school leaders aware of the importance of the new changes and to ensure their full collaboration and commitment to implement the changes on the ground. People, in general, work hard and serve better when they take part in the decision-making process.

Well-educated and qualified leaders have a strong, positive to drastic changes in educational systems. They need to be well-prepared and well-equipped with the knowledge and skills of educational leadership, specifically the knowledge that enables them to lead schools to be centers of excellence in teaching, learning, and capacity-building of students, transitioning schools into learning communities for students and for the local community members. School leaders should have a wealth of experience with the educational process, including teaching, learning, teachers' affairs, professional development, assessment and evaluation, curriculum design, strategic planning, and school budgeting.

Focused group interview with twenty-five teachers revealed the different results presented in Table 1 with the frequencies (how many teachers stated this finding) and percentage of each finding. These findings are the required responses that school leaders have to practice, from the perspective of teachers.

\begin{tabular}{|c|c|c|c|}
\hline No. & Findings & Frequencies & Percentage \\
\hline & Improving the teaching and learning process. & 24 & $96 \%$ \\
\hline & $\begin{array}{l}\text { Improving the quality of the educational facilities, resources, and } \\
\text { infrastructures. }\end{array}$ & 23 & $92 \%$ \\
\hline & $\begin{array}{l}\text { Providing professional development training to teachers or arranging and } \\
\text { inviting well-qualified professionals from different fields to provide the right } \\
\text { training to the teachers. }\end{array}$ & 22 & $88 \%$ \\
\hline & $\begin{array}{l}\text { School buildings should be designed to serve educational purposes and } \\
\text { equipped with the required facilities. }\end{array}$ & 21 & $84 \%$ \\
\hline & $\begin{array}{l}\text { Ensuring that human resources deliver the educational services needed to be } \\
\text { educationally qualified to teach and learn and make students knowledgeable, } \\
\text { skillful, and active citizens. }\end{array}$ & 21 & $84 \%$ \\
\hline & $\begin{array}{l}\text { Educational planning is one of the most important aspects of school } \\
\text { leadership, as leaders need to plan for everything in their schools to move to } \\
\text { the next level of achievement. }\end{array}$ & 20 & $80 \%$ \\
\hline & $\begin{array}{l}\text { Having educational and professional vision to lead their schools and } \\
\text { implement the right change. }\end{array}$ & 20 & $80 \%$ \\
\hline & $\begin{array}{l}\text { Working with teachers and other employees to plan the different activities } \\
\text { that enhance the knowledge and skills of students. }\end{array}$ & 20 & $80 \%$ \\
\hline & Establishing direct and open communication channels with stakeholders. & 20 & $80 \%$ \\
\hline & $\begin{array}{l}\text { Empowering teachers and other staff members to carry out some leadership } \\
\text { responsibilities and take real part in the decision-making process. }\end{array}$ & 20 & $80 \%$ \\
\hline
\end{tabular}

Table 1. Frequencies and percentages of the responses of school leaders to the drastic educational changes in Abu Dhabi Emirate schools 
Focusing on the quality of the teachers in their schools.

Building strong relationships with the local public and private authorities to bring direct support to the school, meet its needs, and overcome the shortage of resources that schools face.

Taking some teaching responsibilities, sharing their experiences, and reflecting with others on how to improve the teaching and learning processes.

Working with teachers and other experts to identify the appropriate technologies for their schools, subjects, and teachers.

Adapting the right curriculum for each subject, in collaboration with educational experts, teachers, and subject matter supervisors.

Supporting teachers to lead their schools to achieve the educational goals.

Committing schools to green school principles in terms of the use of different resources and interactions with the environment.
20

$80 \%$

20

$80 \%$

$76 \%$

19

$76 \%$

18

$72 \%$

18

$72 \%$

18

$72 \%$

Table 1 shows that the core area that has changed rapidly and intensively and considered to be the main source of quality was teaching and learning. Twenty-four teachers $(96 \%)$ stated that school leaders have to improve the teaching and learning process, indicating the importance of this response from the teacher's perspective. It is the responsibility of the educational leaders to take the required actions to improve the quality of teaching and the learning experience of students, leading to an active role for teachers and staff in the development of education in schools today, educational leaders should not be seen as supremely pragmatic and rational while influencing their subordinates through intellectual persuasion. Instead, the term "leadership" must be expanded to include more individuals in the leadership process and emphasize communication throughout the organization (Tierney, 1989; Rosener, 1990; Astin \& Leland, 1991; Bensimon \& Neumann, 1993, as cited in Goh, 2009).

Twenty-three teachers (92\%) stated that it is the responsibility of the educational leaders to improve the educational facilities, resources and infrastructures. Educational leaders are in the right position to make decisions related to providing schools with the required educational facilities, resources and infrastructures. Building the required infrastructure in schools is an important aspect that school leaders need to consider in collaboration with educational, local public, and private community authorities. As a leader, you need to be active and strong to get financial support and improve the infrastructure of the school. Building strong relationships with the local public and private authorities brings direct support to the school to help meet its needs to overcome the shortage of resources that schools face. Local communities are ready to support schools if they are invited and encouraged to do so; in these communities, there are many organizations and companies can help schools and support educational activities. Private companies can support schools with their products; for example, information technology companies can support school computer laboratories with educational software and computers or related equipment. Part of the responsibility of school leaders is the active management to these resources. It is not enough to have the resources and the facilities in schools, as you need active management of these resources, especially with the challenge of adding new facilities or getting more resources to support the educational process. Planning and designing for school facilities have become normal responsibilities for school leaders/administrators (Hilliard, 2011). School leaders can work with teachers and students to use and manage the available resources wisely. Facility management is one of the important functions of the school leader in maintaining safety and health and managing the school building (Chan, McCleod, Bessette, \& Whitson, 2005; Berry, 2002; Dunklee \& Siberman, 1991; Glatthom, 2000; Shideler, 2001).

The developments in the fields of science, technology, humanities, and social sciences required teachers to be up-to-date in their areas and in the science of pedagogy. Teachers need to get annual professional development training to cope with the new developments in different fields. Twenty-two teachers (88\%) have stated that school leaders can respond to teacher needs by providing professional development training to their teachers or arranging and inviting well-qualified professionals from different fields to provide training to the teachers. This is a high percentage and is a key role that teachers want school leaders to play, by encouraging and supporting teachers to participate effectively in professional development workshops; this is accomplished through giving actively-participating teachers rewards and incentives to give such components the right value. Professional development is a key factor in teachers' growth, enriching their experience and skills. Many teachers are not aware of the importance of professional development; for example, 12 to $27 \%$ of teachers, from a study of 2000 , 
believed that professional development activities had improved their teaching practices (National Center for Educational Statistics, 2001). If the teachers do not find an adequate professional development program provided by the district (Lee, 2004/2005), they become more proactive in their continuous improvement (Kent, 2004 as cited in Helterbran, 2010). The implication for teacher training and continuing professional development is to design curricula to allow teachers to negotiate the content, processes, and outcomes as partners in the educational enterprise. Crucially, it means equipping teachers with the capacity to decelerate the pace of the classroom and to support children to take a closer, more detailed analytical view of the problems, concerns, and ideas that they themselves encounter, as Shor puts it, to "extraordinarily re-experience the ordinary" (Shor, 1992, as cited in Williamson \& Morgan, 2009).

Twenty-one teachers (84\%) expressed the view that school buildings should be designed to serve educational purposes and be equipped with the required facilities as one of responses of educational leaders toward educational changes. Teacher considered this response highly important, due to the current problems that teachers experience in some school buildings, which were designed to be accommodations rather than schools. Moreover, twenty-one teachers (84\%) stated that educational leaders need to respond to the human resources that deliver the educational services, as these resources need to be educationally qualified to teach, learn, and make students knowledgeable, skillful, and active citizens. This is due to poor teacher quality and the need to improve the quality of the current teachers and select teachers based on well-defined measurable standards. This will improve the quality of educational systems, which requires educational leaders to give their full support to professional, high-quality teachers. School leaders are the driving force for the development of any aspect of the modern educational systems.

Twenty teachers $(80 \%)$ stated that school leaders have to respond to the different educational changes by having educational and professional vision to lead their schools and implement the right change. This vision should be in alignment with the educational system's vision, clear, and well-focused. This is because educational leaders are agents of change, and to be a successful agent you need to have a realistic and optimistic vision. The mission of the school as an educational organization needs to be defined in such a way to make the vision of the school a reality. Twenty teachers $(80 \%)$ have stated that school leaders will be able to lead schools successfully if they plan well ahead of time. Educational planning is one of the most important aspects of school leadership, as leaders need to plan for everything in their schools to move to the next level of achievement. Furthermore, nineteen teachers $(76 \%)$ stated that school leaders need to work with teachers and other employees to plan the different activities that enhance the knowledge and skills of students: planning teaching and learning activities, curricula, the use of available resources, and to meet the needs of the students and teachers and the teaching process.

Moreover, twenty teachers $(80 \%)$ stated that school leaders have to establish direct and open communication channels with stakeholders. It is their responsibility to create communication channels with students, staff, and parents to communicate and share the school's vision and aims. School leaders should be involved in interactions between all the people in the school; that is why leadership should be shared and distributed (Gronn, 2000; Hargreaves \& Fink, 2006). School leaders have to empower teachers and other staff members to carry out some leadership responsibilities and take real part in the decision-making process; in this spirit, eighteen teachers (72) want educational leaders to empower teachers and other staff members to lead their schools and make real educational decisions. It is very difficult for one or two individuals in a school to perform all needed tasks; therefore, the many aspects of school improvement are a shared experience. For the past decade, many school leaders/administrators used the distribution leadership model, which helps the key leaders/administrators of schools to encourage other faculty and staff to share and coordinate activities at the school level, which may have been coordinated by the school leader/administrator solely in past years (Hilliard, 2011).

Twenty teachers $(80 \%)$ stated that school leaders need to respond to the changes in the educational system by focusing on the quality of the teachers in their schools. School leaders need to identify qualified teachers to serve schools and students. The selection of teachers should be based on qualifications, experiences, motivation, accomplishments, and charisma, which will enable schools to achieve the intended educational vision and goals.

Nineteen teachers $(76 \%)$ stated that school leaders need to respond to the changes in the area of teaching and learning by taking some teaching responsibilities, sharing their experiences, and reflecting with others on how to improve teaching and learning processes. This is moderately important from the teacher's perspective because school leaders and administrators need to know what effective instruction looks like before and when a classroom visit takes place (Hilliard, 2011). School leaders must be part of the teaching process by delivering some lessons in their areas, focusing on leadership skills that can be taught to the students and teachers. Teachers and students need models to follow, and the best available model is the school leader. One of the new missions 
for educational systems is to prepare generations with leadership skills, and this can be met directly by school leaders. School leaders can practice leadership skills that are necessary to develop others; for example, good interpersonal skills, communication, and active listening. Team work is one of the changes that are required for teachers and students. School leaders can respond to this demand by leading teachers and students to work in teams and groups to accomplish certain educational missions.

School leaders get the right educational technologies for the use of teachers and students. In this sense, nineteen teachers $(72 \%)$ want educational leaders to be part of the process of selecting educational technologies, with a moderate importance. With hundreds of technologies in the market, educational leaders need to work with teachers and other experts to identify the appropriate technologies for their schools, subjects, and teachers. Therefore, educational institutions must have adequate infrastructure to accommodate the many technology devices to aid the instructional and learning process. The e-learning opportunities are expanding very fast, and teachers and students must be ready to embrace the new and improved technology (Hilliard, 2011).

Eighteen teachers $(72 \%)$ want educational leaders to respond to curriculum changes, with a moderate importance. School curriculum has witnessed drastic changes over the past two decades. School leaders can take the lead in their schools to adopt the right curriculum in each subject in collaboration with educational experts, teachers, and subject matter supervisors, to ensure that the school curriculum is in alignment with the society's culture and values. Educational leaders can work with different stakeholders inside and outside schools to adapt the most suitable curriculum that can be taught to the students and develop their knowledge and skills. The current role of school leaders is limited and needs to be expanded to allow them to take the lead in identifying the most appropriate curriculum to each subject for each grade.

Teacher leadership is one of the strategies that can help the school leaders respond and implement the changes. In this sense, eighteen teachers (72\%) want educational leaders to support teachers to lead their schools to achieve educational goals, with a moderate importance. According to the Institute of Educational Leadership (IEL) (2008), to cultivate teacher leadership in the school, three conditions should occur, regarding school culture and contexts, roles and responsibilities, and structures. In the school culture and context, the school should focus on reflection, inquiry and learning, encouraging initiatives, setting expectations for teams, sharing leadership, sharing decision-making and responsibilities, working as role models to teach professional values, and spreading the sense of community among teachers to cultivate professionalism. Regarding roles and responsibilities, the school leader requests that all staff respect the teacher leader with subject and instructional expertise, builds trust and good relationships among peer teachers and instructional experts, and understands that teacher leadership is in the center of teaching and learning processes, as opposed to managerial tasks that are assigned by routine, and developing a flourishing interpersonal relationship between teacher leaders and the school principal. The third and last condition is the structure, which is about providing time, access to materials, and places for teacher leadership activities like professional development.

As school responsibility is crucial in preparing the young generation to be environmentally-friendly at the school, national, and international levels, thirteen teachers (52\%) stated that school leaders have to commit their schools to green school principles, $\mathrm{n}$ terms of the use of different resources and interactions with the environment. This can be accomplished through different educational activities throughout the school days and years. Teachers can prepare activities that attract students' interest and prepare them to interact with to the environment. Schools can partner with other schools and companies to promote student awareness of environmental issues.

\section{Conclusion}

A proper response, by school leaders, to educational system changes requires certain preconditions are met. These are related to the quality of the leaders and the power that they have to respond to the changes. School leaders respond positively to changes in educational systems if they are involved, by the top and middle educational leadership, in the preparation and planning of the new changes. School leaders respond to the different educational changes by having educational and professional vision to lead their schools and implement the right change. School leaders have to establish direct and open communication channels with students, staff, and parents to communicate and share the school's vision and aims. School leaders have to be part of the teacher selection process, which should be based on qualifications, experiences, motivation, accomplishments, and charisma. Furthermore, school leaders should build strong relationships with the local public and private authorities to bring direct support to the school and meet its needs.

Educational leaders can work with different stakeholders inside and outside schools to adapt the most suitable curriculum that can be taught to the students and develop their knowledge, personalities, and skills. 


\section{References}

Berry, M. A. (2002). Healthy school environment and enhanced educational performance: The case of Charles Young Elementary School. Washington, DC. Retrieved from http://www.carpet-rug.com/pdfworddocs/ 020112_Charles_Young.pdf

Chan, T. C., McCleod, D., Bessette, H., \& Whitson, J. (2005). The roles of principals in school facility management. The Journal for the Liberal Arts and Sciences, 9(3), 28-33.

Cheng, Y. (2005).A new paradigm for re-engineering education: globalization, localization and individualization. In Y. Cheng (Ed.), Teacher management and educational reforms: paradigm shifts, prospects (pp. 69-89). Dordrecht, The Netherlands: Springer. http://dx.doi.org/10.1007/s11125-009-9113-2

Dunklee, D. R., \& Siberman, R. M. (1991). Healthy buildings keep employees out of bed and employers out of court. School Business Affairs, 57(12), 19-22.

Glatthom, A. A. (2000). The principal as curriculum leader. Thousand Oaks, CA: Corwin Press Inc.

Goh, J. W. (2009). 'Parallel leadership in an "unparallel" world' cultural constraints on the transferability of Western educational leadership theories across cultures. International Journal Leadership in Education, 12(4), 319-345. http://dx.doi.org/10.1080/13603120902980796

Gosling, D. (2009). Educational development in the UK: A complex and contradictory reality. International Journal for Academic Development, 14(1), 5-18. http://dx.doi.org/10.1080/13601440802659122

Gronn, P. (2000). Distributed properties: A new architecture for leadership. Educational Management and Administration, 28(3), 317-338. http://dx.doi.org/10.1177/0263211X000283006

Hargreaves, A., \& Fink, D. (2006). Sustainable leadership. San Francisco, CA: Jossey-Bass.

Helterbran, V. (2010). Teacher leadership: Overcoming I am just a teacher syndrome. Education, 131(2), 1-10.

Hilliard, A. (2011). Current trends in educational leadership for student success plus facilities planning and designing. Contemporary Issues in Education Research, 4(1).

Institute of Educational leadership (IEL). (2008). Teachers leadership in high schools: How principals encourage it how teachers practice it.

Kowch, E. (2009). Capabilities for cyber charter school leadership: An emerging imperative for integrating educational technology and educational leadership knowledge. TechTrends, 53(4).

Lee, H.-J. (2004/2005). Developing a professional development program model based on teachers' needs. Professional Educator, 27(1/2), 39-49.

Liu, Y., \& Dunne, M. (2009). Educational reform in China: Tensions in national policy and local practice. Comparative Education, 45(4), 461-476. http://dx.doi.org/10.1080/03050060903391594

Shideler, L. (2001). A clean school is a healthy school. American School and University, May, 52-56.

Sociological Research Skills. (2011). Research methods. Retrieved from http://www.sociology.org.uk/methfi.pdf

Wallin, D. (2010). Looking to the future: Change leaders for tomorrow's community colleges new directions for community colleges, no. 149, 2010 Wiley Periodicals, Inc. http://dx.doi.org/10.1002/cc.390

Williamson, B., \& John, M. (2009). Educational reform, enquiry-based learning and there-professionalization of teachers. The Curriculum Journal, 20(3), 287-304. http://dx.doi.org/10.1080/09585170903195894

\section{Copyrights}

Copyright for this article is retained by the author(s), with first publication rights granted to the journal.

This is an open-access article distributed under the terms and conditions of the Creative Commons Attribution license (http://creativecommons.org/licenses/by/3.0/). 